\title{
Aging Education: Sociological Analysis on the Social Status Promotion of the Elderly
}

\author{
Xianwei Xia \\ Zhejiang Radio \& TV University, Hangzhou, China \\ Email: xiaxianwei1989@163.com
}

How to cite this paper: Xia, X.W. (2020) Aging Education: Sociological Analysis on the Social Status Promotion of the Elderly. Open Access Library Journal, 7: e6381. https://doi.org/10.4236/oalib.1106381

Received: April 30, 2020

Accepted: June 7, 2020

Published: June 10, 2020

Copyright $\odot 2020$ by author(s) and Open Access Library Inc.

This work is licensed under the Creative Commons Attribution International License (CC BY 4.0).

http://creativecommons.org/licenses/by/4.0/

\section{(c) (i) Open Access}

\begin{abstract}
Chinese society is facing a serious aging problem which causes a continuous decline on the economic, social and cultural status of the elderly due to natural and social factors. Basing on the age stratification theory, social alienation theory, activity theory and subculture theory, this paper conducts sociological analysis on the declining social status of the elderly, discusses the necessity of aging education, and offers suggestions to improve their social status from the perspective of aging education.
\end{abstract}

\section{Subject Areas}

Education

\section{Keywords}

Aging Education, Social Status, Sociological Analysis

\section{Research Questions}

By now, the number of the elderly over 60 years old in China has exceeded 200 million, accounting for $14.9 \%$ of the total population. This proportion is significantly higher than the United Nations traditional social standard for aging of 10\% [1]. China National Committee on Aging predicts that China will enter the peak of aging in the next 20 years. The fact that "get old before getting rich" has become an increasingly prominent problem in China. With the development of social changes, the degenerated physical functions of the elderly and the transformation of their social roles, the ascribed status and achieved status of the old people are declining and the idea of "care for the elderly", "the happy elderly", "the learning elderly" and "the productive elderly" are seriously challenged. As a result, the promotion of the social status of the elderly has become an important 
issue in the current aging education.

\section{Sociological Analysis on the Declining Social Status of the Elderly}

\subsection{Social Status of the Elderly in China in the Transitional Period}

Social status refers to "the relative position in the space of social relations and the relationship between rights and obligations formed around this position" (Zheng Hangsheng, 2003) [2]. This concept is generally used in researches on the social stratification around which the social status of the elderly is formed. It refers to the economic status and social prestige of the elderly, whose level depends on the amount of social resources possessed by the elderly. The social status can be divided into two types: the ascribed and the achieved status. The ascribed status depends on the gender, age and family relationship, which is mainly reflected in the family relationship. The achieved status is often related to the education, occupation and marriage status, which is mainly reflected in the society.

In the social transformation period of China, the declining tendency of social status of the elderly is mainly reflected in the following aspects. Firstly, the ascribed family status is declining. With the change of family structure in China, "core family" has become the mainstream, and the trend of "empty nest" in the family of the elderly is aggravating, which directly leads to the decline of the ascribed status of the elderly. Secondly, the achieved economic status is declining. According to the compulsory implementation of the retirement system, people have to retire when reaching the retirement age whether they are willing or not. This causes dramatic changes on the social role and a decrease of income, which leads to the decline of the achieved status for the elderly. Thirdly, the social and cultural status is declining. Under the dominance of human resource theory, the social competition is intensifying and there is a social cultural environment where the role of young people is emphasized and that of the elderly is ignored, which directly leads to the decline of the social and cultural status of the elderly.

\subsection{Sociological Analysis on the Social Status of the Elderly}

\subsubsection{Age Stratification Theory}

The theory of age stratification, namely the age sociology, is represented by M. W. Riley and originated in the United States in the 1960s. According to the theory, social members are divided hierarchically into the "teenager", "young", "middle-aged" and "old" according to age. When social members change from one age level to another, their social roles and status change accordingly. The age stratification provides a theoretical framework for the cause analysis on the social role transformation and the declining social status of the elderly.

In the social transformation, the "core family" model has become the mainstream and the family roles and status of the elderly has been gradually weakened along with the changes of population policy, the development of social economy and culture and the transition of family models. The changing from 
middle age to old is not only a transition of age but also a change of social roles. In particular, the implementation of the compulsory retirement system, on the one hand, strictly limits the role of the elderly in society by weakening their competitiveness and facilitating the development of young people. On the other hand, the loss of economic and social prestige caused by retirement has marginalized the elderly in the society, resulting in a sharp decline of their social status.

\subsubsection{Alienation Theory}

The theory of social alienation of the elderly is a theoretical system proposed by senior sociologists E. Cumming and W. E. Henry. According to the theory, the communication between the elderly and the society is gradually reduced due to the aging of the physical and psychological functions, which is an inevitable development trend. "As we get older, we start to shrink from our hearts and slowly withdraw from the social activities in which we have to participate throughout the adulthood" (David Popenoe, 2005) [3], and this process of alienation is normal. "The alienation process not only enables the elderly to enjoy their old age, but also meets the needs of the society" and the reason is that the process can "ensure that both the personal satisfaction and the continuity of social system reach an ideal level” (Tang Zhongxun \& Ye Nanke, 1988 [4]; Su Zhongwen, $2012[5])$. This theory provided explanations for the decreasing social status and the low social participation of the elderly.

However, this theory cannot explain all the facts about the low social status and social participation of the elderly in China in the period of social transition. Many old people do not voluntarily withdraw from the social participation and the main social role-play after retirement, nor they are satisfied with the life after the role change. On the contrary, they still have a strong longing for social participations yet limited by the current social development not providing appropriate opportunities and supports for their active participation.

\subsubsection{Activity Theory}

The activity theory is completely opposite to the alienation theory which is proposed by the research center of aging and human development of Duke University. The majority of the elderly remain engaged in the society and activities; the level of activity and the number of participation or alienation are influenced by their early lifestyles and socioeconomic forces. It is not an inevitable nor internal process and it is also necessary for the elderly to maintain or develop appropriate physical, mental and social activities for the happy life in old ages. This theory provides possible explanations for the promoting social status and social participation of the elderly, and also lays a theoretical foundation for the development of aging education.

In the period of social transformation, the actively and willingly social participation of the elderly can not only promote the economic and social development, but also decrease their senses of social alienation. Increasing the amount of social capital can improve the social status of the elderly and realize the value 
of the elderly in their later years to a greater extent, which eventually realizes the "the productive elderly". More and more elderly people voluntary participating in social activities will set a good example for the younger generation, inherit social culture, create social benefits, improve the social image of the elderly, break through the negative impact of the elderly subculture, and improve the marginalized social status of the elderly. "Old but vigorous" is the pursuit of many old people.

\subsubsection{Role-Play Theory and Embeddedness Theory}

The role-play theory initially proposed by Mead George Herbert believes that the individual value is realized in the process of continuous role-playing which is an important form of individual participations in society. The concept of "embeddedness" was proposed by Karl Polanyi in the first place and was later developed into the embeddedness theory by Mark Granovetter. The theory "regards human beings as an actor embedded in a concrete and sustainable social relationship" (Zang Deshun, 2010) [6], with objections to both the under-socialization and the over-socialization.

Based on the previous two theories, the elderly still need to continue the process of socialization and change their role play accordingly from the major social role to the marginal one. This changing process is not carried out alone, but is a series changes of roles. The successful realization of the new role play in society requires the continuous process of socialization, and the aging education is the most effective and important carrier for the continued socialization of the elderly.

\subsubsection{Subculture Theory}

The subculture theory was proposed by the American scholar Roth in 1960s. Subculture, relative to the dominant culture, is the culture held by one group and is different from that of other groups or the whole society. It is generated by different classes, races, religions, regions, ages, genders, occupations, etc. (Huang Ruiling, 2013) [7], and "it is a world within a world, so to speak, but it is a world” (Milton M. Gordon, 1997) [8]. The subculture, different from and even opposite to the dominant culture, is on the edging position. However, in the evolution of society, subculture and main culture can alternate with each other. The subculture theory provides a new researching perspective for the generation of subculture and the decline of the social status of the elderly, that is, to analyze and study the decline of the social status of the elderly on the level of cultural conflict.

In modern society, the elderly are mostly gathered in certain places such as the elderly living center which is a relatively closed activity space, which forms a unique subculture of the elderly. When the old people interact with other groups, especially the young and middle-aged groups, their subculture features will show up. However, conflicts between the elderly subculture and other group cultures have led to the decline of the social status of the elderly, already on the edge of the society, and cannot compete with the dominant group culture. As a result, the 
promotion of the social status of the elderly should guide the active and healthy development of the subculture, integrate with the social dominant culture, ease the cultural conflicts with other groups, and finally achieve the goal of improving the social status of the elderly.

\section{Necessity Analysis on the Development of Aging Education Based on Promoting the Social Status of the Elderly}

The aging education provides non-traditional and special lifelong education activities according to the demand of the development of both the elderly themselves and the society for those recognized by their society in a purposeful and organized way (Ye Zhonghai, 2013) [9]. The aging education, as an important carrier of the continual socialization of the elderly, has positive effects on the social role transformation, identity recognition and healthy development of subculture of the elderly.

\section{1. "The Learning Elderly": Keeping Pace with the Times and Social Development}

It is necessary for the old people to actively integrate into the society in order to improve their social status, and the key point is to keep lifelong learning and to keep pace with the times and the social development. Aging education is an effective way to achieve this purpose.

The old people can move with the times by learning new skills and knowledge in the reeducation. Besides, they can cultivate hobbies, make new friends, enrich spiritual and cultural life, and eliminate their sense of emptiness, loss and even inferiority after retirement. By learning new knowledge, the old can keep pace with the social development, maintain the ability of equal dialogue with other groups in society and decrease the sense of social alienation.

\section{2. "The Adaptable Elderly": Improving the Adaptation of Roles and Continuing Socialization}

The old age is a period of continuing changing and losing roles. The elderly not only go through a role changing from the principal one to the secondary one or even to the marginal one, but also face the risk of losing family roles. Therefore, the adaption of new roles becomes a focusing question in the old's life. There is no doubt that the aging education is the most effective way.

Aging education provides possibilities for the old to fit in with social roles. The aging education pays more attention to the psychological adjustment of the elderly, helps them overcome the harmful mood and live actively, and it can also delay the aging process of their body and mind. As a result, the old can accept the changes and losses of their social roles actively, and in the meantime, they can keep participating in social activities and making contributions to the society, which not only improves the quality of life but also lives a fulfilling and meaningful later life by re-creating their life values. 


\section{3. "The Productive Elderly": Fulfilling the Value of Later Life through Social Participation}

Traditionally, the old people are treated as the "vulnerable groups" which is a marginalized group. In fact, they are still critical human resources pushing forward the social development instead of the weak group in our stereotype, because the social experiences, knowledge and skills they have can never be possessed by other social groups. As a result, improving social participation of the old can facilitate the social development.

The development of aging education will sublimate precious experiences of the elderly and make a further fully use of the energy in their remaining years by constantly updating the concept, adjusting the knowledge structure to keep up with the requirements of the times. In addition, the aging education helps the role shift from the "burden" to "wealth" of the elderly by the development and utilization of senior talents resources. It not only creates wealth for the nation, but also improves the self-supporting ability of the elderly, which is conducive to reducing social burden and promoting social and economic development.

\section{4. "The Happy Elderly": Living a Happy Life by Cultural Integration}

According to ideas of the subculture theory, a subculture group will be formed as long as the interaction between members in the same field goes beyond that with members in other fields. Different age groups have their own cultural activities and contents, and thus the elderly also have their own culture. Generally speaking, the culture of the elderly is practical, simple, introverted, rational and traditional, but often lacks the spirit of the times, the spirit of innovation and the spirit of creation. The culture of the elderly has a subtle influence on the culture of other age groups and the construction of the whole social culture.

The healthy development of subculture of the old can promote the active cultural integration between the old and other groups, maintain a positive interaction with the dominant social culture, and give full play to the benefits of the old' culture and avoid its negative impact. It will further fill the cultural gap between the elderly and other groups, shorten the distance between them, and improve the cultural image and social status of the elderly.

\section{Strategy Analysis on Aging Education Promoting the Social Status of the Elderly}

The International Plan of Action on Ageing adopted by the $46^{\text {th }}$ UN General Assembly stresses that opportunities must be provided for voluntary and capable older people to participate in and contribute to current activities (Liu Tangyu, 2014) [10]. It is shown that the development of human resources for the elderly has attracted the attention from the international community. The development of human resources of the elderly is inseparable from the aging education and it is an important means to promote the social status of old people. 


\section{1. "Capital Increasing": Developing the "Grey Resource" and the Social Capital of the Elderly}

Training is the major method for the development of human resources. The education training is the main channel of human resource development, which is also applicable to the elderly. Actively organizing the elderly to receive learning and training is not only the individual needs, but also an extremely important part of the development of the old's human resources. Therefore, it is necessary to attach importance to the development of aging education, so as to maximize the development of the "gray resource" and increase the social capital of the elderly.

\subsubsection{Strengthening the Legislation of Aging Education}

Legal protection is an inevitable requirement for the educational development and perfect laws and regulations can promote the sustainable and healthy development of the aging education. However, there are no special laws and regulations on aging education in China by now. It is only mentioned in the Law on the Protection of the Rights and Interests of the Elderly that "the elderly has the right to continue to receive education", which cannot play a direct role in promoting the aging education in reality. Accordingly, it is necessary to implement the relevant laws and regulations as soon as possible to promote the development of aging education.

\subsubsection{Building a Lifelong Education System for the Elderly}

The construction of education system can effectively mobilize social resources and promote the development of education. The healthy development of aging education requires the government to actively coordinate the formulation and implementation of various plans for aging education. All kinds of non-governmental organizations and social institutions are also encouraged and supported to participate in aging education in order to strengthen communications between colleges and universities at all levels and universities for the aged, and further promote the socialization and marketization of aging education. And the healthy development of aging education can meet the education and training needs of the elderly and construct a lifelong education system for the elderly with various levels and types.

\subsubsection{Developing Community Aging Education}

Community education is an important carrier for the implementation of aging education. Compared with other forms of universities for the aged and self-learning, community education provides great convenience for the life of the elderly and also provides a more formal and economic learning platform, which is conducive to the overall civilization construction and development of the community. Thus, the government should give policy and financial support to the development of community education for the elderly to boost the development of community education. 


\section{2. "Body and Mind Entertainment": Conducting "Elderly Education" and Promoting the Role Adaptation of the Elderly}

"Elderly education" ("Le Ling education") originates from Singapore where people call the senior citizens as "Le Ling people", which shows great importance and respect for the elderly. The elderly education plays an important role in activating the social life of the elderly and also has positive effects on the adaptation of social roles in their later age.

\subsubsection{Developing Preparatory Education of the "Role Adaptation"}

The elderly who just retired from the main roles in society possibly have a strong sense of discomfort to their life after retirement, which leads to psychological emptiness and even bad effects on their physical and mental health. In this case, the elderly receiving the preparatory education before retirement can help them better prepare for the role adaptation after retirement. The establishment of preparatory school can make the elderly who are about to retire make more reasonable use of their old age time by planning their life after retirement in advance, and realize their life value.

\subsubsection{Developing the Enjoyment Education with "Role Integration"}

Drawing lessons from the "YAH! Community College" in Singapore, the development of enjoyment education can make educational compensation for missed education in youth and meet the old people's learning demands. Relying on the community resources, the enjoyment education develops courses with different levels and various types to meet the different learning needs of the elderly by invigorate the "role integration", and eventually realizes the idea of "the learning and happy elderly".

\section{3. "Influence Extending": Promoting Social Participation and Social Influence of the Elderly}

Social participation is a kind of behavior model in which participants realize their own value through social labor or social activities in the process of social interaction (Zhang Kaiti, 2008) [11]. Old people's social participation refers to their participation in a series of political, economic, cultural and social activities including interpersonal communications, labor participation, leisure activities and social interactions. Only if the elderly actively participate in the society, can they better improve their social influence and social status.

\subsubsection{Enhancing the Propagation to Guide Public Opinions for Social Participation of the Elderly}

The government should utilizevarious publicity tools to widely propagate the value of social participation of the elderly, and honor those with outstanding contributions. The social forces should be encouraged to support the social activities of the elderly and develop the aging education. It can give full play to their expertise and remaining energies and satisfy their pursuit of higher life value. 


\subsubsection{Broadening the Ways to Build Platforms for Social Participation of the Elderly}

By using various resources of the aging education, the voluntary participation in social services of the elderly should be encouraged and those old-age associations that provide platforms, convenient conditions and policy supports for their social participation should be established as well. Besides, we should encourage the old-age communities to provide all kinds of voluntary services or production activities for the society by using their expertise and skills. On the one hand, the old people's activities can provide necessary services for the society, realize their life value, and promote the social development. On the other hand, they can promote the economic status of the elderly by generating economic benefits, improve social images of the elderly as "vulnerable groups", and finally achieve "the productive elderly".

\subsubsection{Providing Institutional Guarantees for Social Participation of the Elderly}

The conduction of relative activities of the aging education requires to mobilize corresponding resources and supports, and therefore the state should provide policy and legal supports and guarantees for the aging education and social participation. The leading role of the government should be given fully play to improve the policy system for aging education and social participation of the elderly, and to provide support and convenience for their social participation by integrating various aging education resources together with forces of social groups.

\section{4. "Culture Integration": Spreading "Subculture of the Elderly" and Promoting Cultural Integration}

In the process of interaction with each other, the senior group has formed a unique subculture of the elderly and the formation of this cultural circle shows the characteristics and interests of the elderly. However, when communicating with other groups, the elderly often feels culturally isolated in varying degrees, which affects the social participation and status of the elderly. Therefore, the dissemination of the elderly subculture is an inevitable choice for promoting cultural integration of the elderly. The propagation of subculture is the purposes, approaches and methods related to subculture on the basis of the propagation of the dominant culture.

\subsubsection{At the Micro Level: Cultivating the Cultural Consciousness of the Elderly}

The healthy development of the elderly subculture depends on efforts and self-consciousness of the elderly their own. The aging education can cultivate the cultural consciousness and the ability of cultural choice of the aged, which lays the foundation for the healthy development of the elderly subculture. Through active self-construction, cultural screening and dissemination, the elderly can narrow the cultural gap with other social groups, improve the social image of the elderly, and finally achieve their social status. 


\subsubsection{At the Median Level: Active Cultural Propagation and Guidance of Educational Institutions for the Elderly}

The aging education is an important way of propagating subculture of the aged. Through the active choice of the aging education, we can guide and spread the elderly subculture in a good way and improve the cultural quality of the elderly subculture. What's more, the active organization of social public welfare activities and the spread of the elderly subculture will provide opportunities for other groups of society to know better and have a new idea of the elderly groups. All above will improve the social influence of the elderly.

\subsubsection{At the Macro Level: Relying on Legal Protection and Resource Integration to Lead Development}

At the macro level, the government and relevant cultural departments should support the integration of elderly subculture and social dominant culture, promoting a healthy and active elderly subculture through cultural publicity, screening and integration, and the departments should provide support for the development of elderly culture through laws and regulations of the aging education. In addition, the integration of institutions such as senior universities and community education provides the platform guarantee and professional supports for the publicity, integration, merger of the elderly subculture.

\section{Conclusion}

The reducing of the social status of the aged is a social problem that cannot be ignored. There are both natural and social factors behind this issue. The development of aging education can not only give full play to the remaining energies of the elderly to realize their social value, improve their economic, social and cultural status, but also promote the harmonious development of society and make contributions to the realization of the great Chinese dream.

\section{Acknowledgements}

This paper is supported by the special project "Epidemic Situation and Education" (No. 2020YQJY006) of Education Science Plan of Zhejiang Province in 2020 .

\section{Conflicts of Interest}

The author declares no conflicts of interest regarding the publication of this paper.

\section{References}

[1] The Accelerating of Aging Population: 15\% of the Citizen Are over 60 Years Old. http://finance.ifeng.com/a/20140220/11707493_0.shtml

[2] Zheng, H.S. (2003) Introduction to Sociology New Edition. China Renmin University Press, Beijing, 218.

[3] Popenoe, D. (2005) Sociology. Translated by Li Qiang, et al., China Renmin University Press, Beijing, 334. 
[4] Tang, Z.X. and Ye, N.K. (1988) Seven Theoretical Models of Geriatric Sociology Abroad. Social Sciences Abroad, 11.66.

[5] Su, Z.W. (2012) Social Status of the Elderly from a Social Participation Perspective: A Case Study of Jilin Province. Northeast Normal University, Changchun, 13.

[6] Zang, D.S. (2010) Granovetter's Embeddedness Theory and the Latest Developments of the New Economic Sociology. Journal of Graduate School of Chinese Academy of Social Sciences, 1, 108-114.

[7] Huang, R.L. (2013) Subculture-The Concept and Evolution. Foreign Theoretical Trends, 3, 44-49.

[8] Gordon, M.M. (1997) The Concept of the Sub-Culture and Its Application. In: Gelder, K. and Thornton, S., Eds., The Sub Culture Reader, Routledge, London, 40-43.

[9] Ye, Z.H. (2013) Several Basic Issues with Education of the Elderly. Modern Distance Education, 6, 11-16.

[10] Liu, T.Y. (2014) On the Development of Human Resources for the Aged in China. Inquiry into Economic Issues, 7, 70-72.

[11] Zhang, K.T. (2008) Study on Social Activity and Mental State of the Elderly in Urban/Rural China. China Social Press, Beijing, 134. 